to the study of adverse reactions only (13 October, p 940). Properly, epidemiological pharmacology is the study of human populations exposed to pharmacological agents. However, it is only one of the tools used in social pharmacology. This wideranging discipline, analogous to social medicine, is concerned with the effects on society of exposure to drugs, the reasons for that exposure, and the social factors influencing the use of drugs. ${ }^{1}$ These factors include the economic and political ones affecting prescribing practice. I therefore support Professor Lawson's plea that more pharmacoepidemiologists should be encouraged and hope that they would come from a wide range of disciplines.

TIMOTHY JERRAM

$$
\begin{aligned}
& \text { High Royds Hospital, } \\
& \text { Ilkley LS29 6AQ } \\
& 1 \text { Venulet P. From experimental to social pharmacology: } \\
& \text { a natural history of pharmacology. Int } \mathcal{f} \text { Clin } \\
& \text { Pharmacol 1974;10:302-5. }
\end{aligned}
$$

\section{Who needs clinical pharmacology?}

SIR,-It is open season on clinical pharmacology in the medical weeklies. Hard on the heels of an Italian group accusing clinical pharmacology of having lost its way ${ }^{1}$ comes a distinguished British professor of medicine asking who needs clinical pharmacology (27 October, p 1119).

At least our Italian colleagues did us the courtesy of presenting some data, on which they based their conclusions. Professor J R A Mitchell chooses instead his review of a textbook of clinical pharmacology (of which incidentally he did not disapprove) to vent his spleen on a discipline with which I had always assumed he enjoyed cordial relations.

His attack is not only on clinical pharmacology. He apparently does not believe that pharmacology should ever have been separated from biochemistry and physiology. This is an argument which I had thought was settled some 30 years ago. Rereading some of Professor Mitchell's own substantial scientific contributions, one would have perhaps expected a slightly more gracious attitude towards the achievements of pharmacology, since he has relied on them quite heavily. He further denigrates pharmacology by placing it in an inferior position to therapeutics, which he finds difficulty in separating from medicine. It is sad that he does not appreciate the continuity of the discipline of pharmacology, stretching from the study of the fundamental properties of a drug (including its chemistry and mode of action) to investigation of the drug in volunteers and patients before its introduction into medicine. There is no justification for choosing any one part of this process as being more important than another: the chemist provides the tools for the pharmacologist to investigate and the doctor to use.

He uses the example of the time course of the hypotensive effect of atenolol to belittle human pharmacology. Any clinical pharmacologist worth his salt would have told him that neither the kinetics of a $\beta$ blocker nor its dynamics as measured by inhibition of isoprenaline induced tachycardia gives any guidance to the duration of hypotensive activity of agents in this group.

Acadenic and industrial clinical pharmacology are rohust enough to withstand this baseless type of attack, but the part of the discipline working within the National Health
Service is more fragile. Professor Mitchell is indeed fortunate to work in an environment where his colleagues in gastroenterology, oncology, cardiology, and endocrinology are so well informed in clinical pharmacology matters; in this he must be virtually unique. The encouragement of effective, safe, and economical prescribing (which are the aims of clinical pharmacology) within the National Health Service deserves more encouragement from Professor Mitchell than he seems prepared to give.

Professors of medicine might be better advised to tend to the not inconsiderable problems in their own discipline $\mathrm{e}^{23}$ and put their own houses in order before interfering in matters which they clearly do not understand.

Department of Clinical Pharmacology,

University of Liverpool,

1 Bonati M, Tognoni G. Has clinical pharmacology lost its way ? Lancet $1984 ; \mathrm{i}: 556-8$.

lort WS. Death of the professor of medicine. Lance 1970;i :401-2.

3 Peart WS. Rebirth of the professor of medicine. Lancet $1983 ; \mathrm{i}: 810-2$.

SIR,-Professor J R A Mitchell uses a book review to criticise the relevance of basic medical sciences (including pharmacology) and of clinical pharmacology to clinical medicine. He shares the opinion of Macfarlane Burnet that "Almost none of modern basic research in the medical sciences has any direct or indirect bearing on the prevention of disease or on the improvement of medica care." Although the strength of an argumen is not measured by Nobel laureates, I believe that the major contributions of Yalow Schally, Samuelson, and Vane cast doubt on that view. This year's Nobel prize award to Cesar Milstein and Georges Kohler for their work on monoclonal antibody production is another example of the relevance of basic medical research to the progress of clinical medicine.

Professor Mitchell sees the clinician as a car driver and the scientist as an engineer or designer. He forgets that medical students (for which Girdwood's book was written, after all) may wish to become scientists instead of, or as well as, clinicians. Even the full time clinician will benefit from a knowledge of science, as the driver does from some understanding of engineering and design.

His second doubt concerns the existence of clinical pharmacology as a separate discipline. He contends that it attempts to fuse two disparate parts (pharmacology and therapeutics), which should have been kept separate. As someone concerned in both activities, I believe that it is precisely the failure of some physicians to recognise the natural unity of the two that has led to the necessity for the growth of clinical pharmacology. My own experience has convinced me that clinical pharmacologists can have fruitful collaboration with colleagues in the "organ based" specialties, and I certainly do not feel unwanted or unneeded.

Professor Mitchell tells us that the main problems in medicine are whether to use drugs rather than what the drugs are or even how to use them. To return to his own chosen analogy: if he helieves that the decision about whether to drive a car can be made without reference to the ability to recognise the appropriate vehicle and handle it properly, I hope I am well away from the public highway when he sallies forth on his next excursion into unfamiliar territory.

Philip Routledge

Department of Pharmacology and Therapeutics, University of Wales College of Medicine,

SIR,-I had a profound sense of déjà vu when reading Professor J R A Mitchell's review. Surely we do not have to reopen the issue of whether clinical pharmacology is a discrete discipline: its permanent posts, its own journals, its national and international meetings, its role in district general hospitals ${ }^{1}$ all attest to the fact that it is established. What is more alarming is the curious assertion that medical science can be neatly slotted into named files-pharmacology into one, for example, and therapeutics into another, and never should the twain meet. This view ignores the essential issue that drugs are chemicals and that when a doctor administers a chemical to a patient looking for its effect his or her observations will be incomplete if he ignores the fact that the chemical must be absorbed, distributed round the body, and eliminated from it. It is not necessary to carry in the mind the rate constants for transfer of drug from one mathematical body compartment to another, but some knowledge of a drug's kinetics may help to explain why treatment fails-for example, because of enzyme induction-or gives adverse resultsfor example, because of impaired renal function. Awareness of these problems has come not from therapeutists but from clinical pharmacologists. I agree that the average car driver need not understand the structural formula of petrol, but it may help to know when the fan belt is slack. To regard it as sufficient knowledge about a drug to "see if it works" is to aspire to a knowledge that is less than complete. Who needs clinical pharmacology ? Professor Mitchell, perhaps you do.

Peter Bennett

Clinical Pharmacology Unit, Royal United Hospital, Bath BA1 3NG

Pearson RM, Muclow JC. Clinical pharmacology in practice. F $R$ Coll Phys Lond $1984 ; 18: 219-21$.

\section{Maggots dyed with chrysoidine}

SIR,-We must concur with Mr G M Sole (20 October, p 1043) about the strong circumstantial evidence for the possible carcinogenic properties of chrysoidine. Not only has this been shown to be carcinogenic in mice, as stated; it is also a potent mutagenic agent in bacteria. ${ }^{1}$

Transitional cell carcinoma is rare in the younger patient. We are currently treating only two young men, both anglers, with this diagnosis. One man of 35 presented eight years ago and has multiple invasive tumours and dysplasia of the whole urothelium, recently necessitating a nephroureterectomy. $\mathrm{He}$ is a non-smoker who has worked all his life in computer programming but, when fishing, used bronze maggots for at least five years. The second man, aged 26 , has undergone cystoscopy twice, which has shown a single well differentiated tumour and area of dysplasia on each occasion. $\mathrm{He}$ is a smoker but again has had no industrial exposure to 
carcinogens. He too has used bronze maggots over several years.

The youth and lack of history suggestive of genetic predisposition in these patients would seem to constitute further evidence for banning the use of chrysoidine for angling, at least until more conclusive studies have been performed.

J A Massey

R C L FENELEY P H ABRAMS

\author{
Ham Green Hospital,
Bristol BS20 0HW \\ 1 Garner RC, Nutman CA. Testing of some azo dyes \\ and their reduction products for mutagenecit \\ using Salmonella typhimurium TA 1538. Mutat
}

SIR,-Mr G M Sole raises the possibility of a genetic predisposition to bladder cancer (20 October, p 1043). An answer may be found in the $\mathrm{N}$-acetyltransferase phenotype status of the two brothers. Populations of slow and fast acetylators have been identified and an association between transitional cell bladder cancer and slow acetylation established. ${ }^{12}$ Slow acetylation is an autosomal recessive phenotype which may have been inherited by both brothers with a resultant increased risk from their exposure to smoking and chrysoidine.

Department of Urology,
St Mary's Hospital,

1 Cartwright RA, Glashan RW, Rogers HJ, et al. Role of $N$-acetyltransferase phenotypes in bladde carcinogenesis: a pharmacokinetic epidemiologica 2 Evans DAP, Eze LC, Whibley EJ. The association of the slow acetylator phenotype with bladder cancer. the Med Genet 1983;20:330-3.
f

\section{Plasma exchange in rapidly progressive crescentic glomerulonephritis}

SIR,-We were interested in Dr Terry Hamblin's comments on the problems of using randomised controlled trials to study the effectiveness of plasma exchange in treating rapidly progressive crescentic glomerulonephritis (29 September, p 779). Our own study was affected by operational difficulties in that plasma exchange was not always fully available and we felt that such aggressive treatment should be started as soon as possible after biopsy diagnosis. ${ }^{1}$ Intravenous pulses of methylprednisolone can be given at any time of the day or night and are cheaper and easier to administer than plasma exchange and so tended to be used when trained medical staff were in short supply-for example, during weekends or holidays. However, weekends, holidays, staff promotion, or sickness tend to be random variables themselves or, if regularly recurring, of little pathogenic significance.

From 1977 to 1981, 27 patients on Merseyside with rapidly progressive crescentic glomerulonephritis were treated either with plasma exchange (13) or pulse methylprednisolone (14) depending on the availability of the former and the balance within the series. All patients also received oral prednisolone and azathioprine or cyclophosphamide. The two groups were well matched for factors affecting prognosis such as age, severity of disease, and incidence of associated disorders such as polyarteritis nodosa. Both treatments were equally effective in reversing progression into renal failure: 7 patients given plasma exchange and 11 patients given pulse methylprednisolone responded promptly within one month of starting treatment.
This was in striking contrast to an earlier series of 17 comparable patients treated in Liverpool from 1972 to 1979 with oral therapy alone, when only one patient responded. In consequence we no longer use plasma exchange routinely in rapidly progressive crescentic glomerulonephritis mediated by immune complexes, and all patients are given pulse methylprednisolone.

Further anaiysis of the responding patients showed that the follow up dose of oral steroids may be critical in at least the first six months. ${ }^{2}$ In patients whose renal function remained stable the dose of prednisolone was reduced from $30 \mathrm{mg}$ daily after six to eight weeks to $15-20 \mathrm{mg}$ at three months, 10-15 mg at six months, and 5-10 mg after one year. In patients who relapsed doses of prednisolone had been reduced more rapidly. Some patients seemed sensitive to a reduction in dose even after two years.

Great care therefore needs to be taken, especially for patients with signs of residual disease and for whom replacement therapy would be difficult. Indeed these patients may need to take both prednisolone and azathioprine indefinitely in maintenance doses similar to those used for patients with stable renal allografts and systemic lupus erythematosus. Fortunately such treatment is well tolerated, and serious side effects are rare.

J M BONE

Regional Renal Unit,

Royal Liverpool Hospital,

South Cleveland Hospital

Middlesbrough, Cleveland

1 Stevens ME, McConnell M, Bone JM. Aggressive treatment with pulse methylprednisolone or plasma exchange is justified in rapidly progressive glomerulonephritis. Proc Eur Dial Transplant Assoc
1982;19:724-31. Stevens ME Bone

dosage dosage in rapidly progressive crescentic glomerulone-
phritis (RPCGN) successfully treated with pulse phritis (RPCGN) successfully treated with pulse (Px). Proc Eur Dial Transplant Assoc (in press).

\section{Algorithm for modified alkaline} diuresis in salicylate poisoning

SIR,-The algorithm for treating salicylate poisoning suggested by Dr I J Gordon and others (20 October, p 1039) gives guidelines on treatment when serum salicylate concentrations are $500-800 \mathrm{mg} / \mathrm{l}$. The alkalinising regimen they describe was not used therapeutically for more severe poisoning. We describe a 52 year old woman who took three separate overdoses of aspirin. These allowed us to compare three different treatments. On each occasion the patient had gastric lavage and activated charcoal.

The first overdose produced a serum salicylate concentration of $790 \mathrm{mg} / 1$ five and a quarter hours after ingestion. Treatment was by forced simple diuresis (urine output of $5120 \mathrm{ml}$ over 14 hours, urine $\mathrm{pH} \leqslant 6$ throughout). The serum salicylate concentration fell with a half life of 24 hours.

Two weeks later another overdose produced a serum salicylate value of $830 \mathrm{mg} / \mathrm{l}$ nine and a half hours after ingestion. Initial treatment was by forced simple diuresis (urine output $7966 \mathrm{ml}$ over 15 hours, urine $\mathrm{pH} \leqslant 6$ ), but after 15 hours' treatment the serum salicylate concentration was still $800 \mathrm{mg} / \mathrm{l}$ and fluid overload had occurred. Treatment was changed to an alkalinising regimen (652 mmol(mEq) bicarbonate over 16 hours), and diuretics were given. This produced a diuresis of $5430 \mathrm{ml}$ of urine over 16 hours. The alkalinising regimen did not alter the urine $\mathrm{pH}$ during the initial 10 hours of the regimen (although blood $\mathrm{pH}$ rose to $7 \cdot 56$ ), and the serum salicylate half life remained 24 hours. The final six hours of the regimen produced a urine $\mathrm{pH}$ of 8 , however, with successful salicylate clearance (serum half life eight hours).
The serum salicylate concentration was $630 \mathrm{mg} / \mathrm{l}$ when urinary alkalinisation was achieved.

Two months later another overdose produced a serum salicylate concentration of $840 \mathrm{mg} / 1$ seven and a half hours after ingestion. On the modified alkaline diuresis method of Dr Gordon and his colleagues blood $\mathrm{pH}$ rose to 7.6 but urinary $\mathrm{pH}$ remained $\leqslant 6$. Serum salicylate fell with a half life of 25 hours. Electrolyte values were normal at presentation, except bicarbonate $(15 \mathrm{mmol} / \mathrm{l})$, but the potassium concentration rose to $6.6 \mathrm{mmol}$ $(\mathrm{mEq}) / \mathrm{l}$ and urea to $12.6 \mathrm{mmol} / \mathrm{l}(76 \mathrm{mg} / 100 \mathrm{ml})$ two hours after the start of the alkalinising regimen. Potassium was excluded from the regimen and six hours later the serum potassium concentration had fallen to $2.8 \mathrm{mmol} / \mathrm{l}$.

Urinary clearance of salicylate is related to urinary $\mathrm{pH} .{ }^{1}$ In severely poisoned patients it is not always possible to alkalinise the urine with the regimen described. Rapid changes in potassium concentration may occur in patients treated with alkalinisation. It is unclear whether these electrolyte changes are more dangerous than the salicylate itself. We believe that neither forced alkaline diuresis nor modified alkaline diuresis is entirely satisfactory in severe $(\geqslant 790 \mathrm{mg} / \mathrm{l})$ salicylate poisoning.

$S$ W COPPACK C S Higgens

Queen Mary's Hospital,
London SW15 5PN 1 Prescott LF, Balali-Wood M, Critchley JAJH,
Johnson AF, Proudfoot AT. Diuresis or urinary
alkalinisation for salicylate poisoning. $\mathrm{Br} M$ Med $\mathcal{F}$ 1982;285:1383-6.

Failure of the cervical cytology screening programme

SIR,-Cervical cytology is in the news. September and October have seen a flurry of articles in the $B M \mathcal{H}$, the Lancet, and the Fournal of the Royal College of General Practitioners. The DHSS has also recently issued its latest advice on cervical screening based on the report of the committee on gynaecological cytology. Unfortunately the advice from the DHSS, the message from the recent papers, and the general private undercurrents from those working in cytology about what would be an appropriate policy fail to tally.

Official policy continues to recommend smears $(a)$ at five year intervals for women aged 35 and over, (b) for women who have been pregnant three or more times, and $(c)$ after every pregnancy. For younger women the new recommendation is a cervical smear when the woman first presents for contraception and thereafter at ages 20,25, etc, and not at intervening ages. Although an attempt has been made to simplify the previous muddled recommendations issued by the DHSS, there are still inconsistencies. For example, the DHSS attempts to reduce the number of what it sees as unnecessary smears being taken in the young age groups but then recommends that smears should be taken when women first present for contraception. Surely it would be sensible to add the rider "within the first two years of being sexually active," as it seems unnecessary to take a cervical smear from someone who has never been sexually active or who has just started having intercourse.

Current wisdom also has it that the wrong women-that is, young women-are the ones getting smears but not the cancer, whereas older women are getting the cancer but not the smears. Data support this to a certain extent, but, although most cases of cervical cancer 